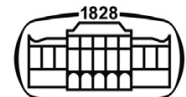

AKADÉMIAI KIADÓ

European Journal of Microbiology and Immunology

10 (2020) 3, 178-185

DOI:

$10.1556 / 1886.2020 .00029$

(c) 2020 The Authors

ORIGINAL RESEARCH PAPER

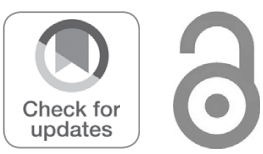

${ }^{\dagger}$ Hagen Frickmann and Andreas Zautner contributed equally to this work.

${ }^{*}$ Corresponding author. Institute for Medical Microbiology, University Medical Center Göttingen, Kreuzbergring 57, 37075, Göttingen, Germany, Tel.: +49551395927. E-mail: azautne@gwdg.de

\section{Evaluation of the Xiamen AmonMed Biotechnology rapid diagnostic test COVID-19 IgM/IgG test kit (Colloidal gold)}

\author{
ANJA DÖRSCHUG ${ }^{1}$, JULIAN SCHWANBECK ${ }^{1}$ (D), \\ ANDREAS HAHN ${ }^{2}$, ANKE HILLEBRECHT ${ }^{3}$, \\ SABINE BLASCHKE ${ }^{3}$, UWE GROß ${ }^{1}$, \\ MARKUS M. HEIMESAAT ${ }^{4}$, HAGEN FRICKMANN $^{2,5 \dagger}{ }^{\circ}$ and \\ ANDREAS E. ZAUTNER ${ }^{1 \dagger *}$ (1)
}

\author{
${ }^{1}$ Institute for Medical Microbiology, University Medical Center Göttingen, Göttingen, Germany \\ ${ }^{2}$ Institute for Medical Microbiology, Virology and Hygiene, University Medicine Rostock, Rostock, \\ Germany \\ ${ }^{3}$ Interdisciplinary Emergency Department, University Medical Center Göttingen, Göttingen, \\ Germany \\ ${ }^{4}$ Department of Microbiology and Hygiene, Charité - University Medicine Berlin, Berlin, Germany \\ ${ }^{5}$ Department of Microbiology and Hospital Hygiene, Bundeswehr Hospital Hamburg, Hamburg, \\ Germany
}

Received: August 28, 2020 - Accepted: September 9, 2020

Published online: September 25, 2020

\begin{abstract}
Introduction: To efficiently monitor the COVID-19 pandemic for surveillance purposes, reliable serological rapid diagnostic tests (RDTs) are desirable for settings where well-established high-throughput bench-top solutions are not available. Here, we have evaluated such an RDT. Methods: We have assessed the Xiamen AmonMed Biotechnology COVID-19 IgM/IgG test kit (Colloidal gold) and the EUROIMMUN benchtop assay with serum samples from patients with polymerase chain reaction (PCR)confirmed COVID-19 disease. Samples from patients with Epstein-Barr-virus (EBV) infection and blood donors were used for specificity testing. Results: For the colloid gold rapid test and the EUROIMMUN assay, the study indicated overall sensitivity of $15.2 \%$ and $67.4 \%$, respectively, while specificity of $99.0 \%$ and $97.9 \%$ with the blood donor sera, as well as $100 \%$ and $96.8 \%$ with the EBV-patients, were observed, respectively. An association of the time period between positive PCR results and serum acquisition with serological test positivity could be observed for the immunologlobulin $G$ subclass of the EUROIMMUN assay only. Conclusions: In spite of acceptable specificity of the assessed RDT, the detected poor sensitivity leaves room for improvement. The test results remain difficult to interpret and therefore the RDT can currently not be recommended for routine diagnostic or surveillance use.
\end{abstract}

\section{KEYWORDS}

COVID-19, SARS-CoV-2, rapid diagnostic testing, point-of-care testing, surveillance, serology, epidemiology

\section{BACKGROUND}

COVID-19 (Corona Virus disease), associated with pandemic spread starting from Wuhan, China in December 2019 and caused by SARS-CoV-2 (Severe Acute Respiratory SyndromeCorona Virus-2), was first observed in Europe at the beginning of 2020 [1]. In the meantime, surveillance and containment became a global concern.

As recently discussed for sexually transmitted infections (STIs), diagnostic approaches can help to limit the transmission of infectious agents [2-5]. Diagnostic results can further 
contribute to the estimation of risk behavior, which facilitates transmission of infectious agents, on the population level [6]. To support the diagnosis of COVID-19 and associated containment purposes, first real-time polymerase chain reaction (PCR) schemes targeting SARS-CoV-2 were rapidly provided [7].

To circumvent laborious and demanding in-house realtime PCR, cartridge-based [8-14] and other [15-18] fullyautomated molecular tools for the detection of SARS-CoV-2 were introduced to allow more rapid or point-of-care testing (POCT). For mass testing purposes, pooling and sequencing were discussed; while CRISPR gene-editing tools combine good sensitivity and specificity with the easy-to-apply lateral flow technology [19].

Although molecular diagnostic approaches are required for the identification of infective individuals, copy numbers of viral pathogens decrease in the course of the infection [17, 20]. It is therefore unlikely that all individuals with SARSCoV-2 infections will be detected within the replicative period. Accordingly, serological assessments are an alternative for surveillance purposes. In resource-limited settings, POCT approaches may provide readily available and easyto-apply tools.

Previously described serological POCT tools have shown test characteristics with room for improvement. While reported specificity of immunochromatographic and enzyme linked immunosorbent assay-(ELISA-)based was usually above $95 \%$, heterogeneous sensitivity with widely varying values between less than $70 \%$ and more than $90 \%$ was described depending on the populations assessed [21-34]. In these studies, false-positive results were described to be associated with rheumatoid factor-immunoglobulin $M$ (IgM), and urea dissociation was suggested to overcome this problem [21]. In a meta-analysis, sensitivity of gold immunochromatography assays (GICA) was slightly better than sensitivity of ELISA approaches [22]. Heat inactivation of sera was described as not relevantly interfering with the reliability of immunochromatographic test assays [28]. Time since positive PCR testing has been reported to be crucial for optimum serological POCT sensitivity, with best results at least 14 days after the positive PCR result [31]. At later postinfectious stages, serology can become negative again [35].

In summary, there are several limitations of presently available diagnostic POCT options [36-38] as well as gaps of knowledge regarding the appropriate interpretation of their results. For serological test assays, in particular, considerable variability of their results has been reported [39]. Patient age has been shown to play a role for measured antibody titers [40]. While binding antibodies seem to be more sensitive than neutralizing antibodies [40], antigenic cross-reactivity between SARS-CoV-2 and human coronaviruses 229E and OC43 has been described [41].

To provide another piece of the puzzle regarding the assessment of serological POCT assays for COVID-19, the rapid diagnostic test (RDT) COVID-19 IgM/IgG test kit (Colloidal gold, Xiamen AmonMed Biotechnology Co., Ltd., Haicang District, Xiamen, China) was assessed in direct comparison with the EUROIMMUN benchtop assay, which shows imperfect performance characteristics as well [31, 32, 42-53]. Tests were performed with serum samples from patients with PCR-confirmed COVID-19 disease. For specificity testing purposes, samples from patients with EpsteinBarr-virus (EBV) and blood donors were used.

\section{MATERIALS AND METHODS}

\section{Sample collections}

Three serum sample collections were included in the assessment. The first collection consisted of samples from 46 PCR-confirmed COVID-19 patients. PCR had been performed from nasopharyngeal swabs. The time between the positive PCR result and the acquisition of the serum samples was documented in 27 out of $46(58.7 \%)$ cases, ranging from 0 to 60 days (median: 21 days, mean: 20 days, standard deviation (SD): 19.2 days). The second collection consisted of samples from 96 blood donors taken in 2015, before the onset of the COVID-19 pandemic. Finally, a third collection contained $31 \mathrm{EBV}$-positive serum samples, which were used to assess the effects of polyclonal B-cell stimulation.

Ethical clearance allowed a fully anonymized use of sample materials only. Accordingly, patient details cannot be provided.

\section{Serological assays}

Applied serological assays comprised the COVID-19 IgM/ IgG test kit (Colloidal gold, Xiamen AmonMed Biotechnology Co., Ltd., Haicang District, Xiamen, China; referred to as "AmonMed assay" in the following), and the EUROIMMUN Covid-19 IgG/IgA assay (EUROIMMUN, Lübeck, Germany; referred to as "EUROIMMUN assay" in the following). All tests were performed as described by the manufacturer's instructions. The AmonMed assay as the RDT of interest was performed in duplicate to confirm its positivity rates (see Fig. 1).

\section{Real-time PCR testing}

Respiratory sample materials from the patients with suspected or confirmed COVID-19 were subjected to real-time PCR for SARS-CoV-2. Screening was performed applying the Genesig Real-Time PCR Coronavirus (COVID-19) assay (Primerdesign Ltd., Chandlers Ford, UK) and first-time positive results were confirmed using automated Cepheid Xpert Xpress SARS-CoV-2 PCR (Cepheid, Sunnyvale, CA, USA). The assays were performed as described by the manufacturers.

\section{Statistical assessment}

Descriptive analysis was performed including all sample collections and test assays. Sensitivity of the serological assays was calculated with the sample collection from the suspected or PCR-confirmed COVID-19 patients. Thereby, patients with positive PCR results were considered as confirmed positive cases. The effect of the number of days between positive PCR results and the serum sample 


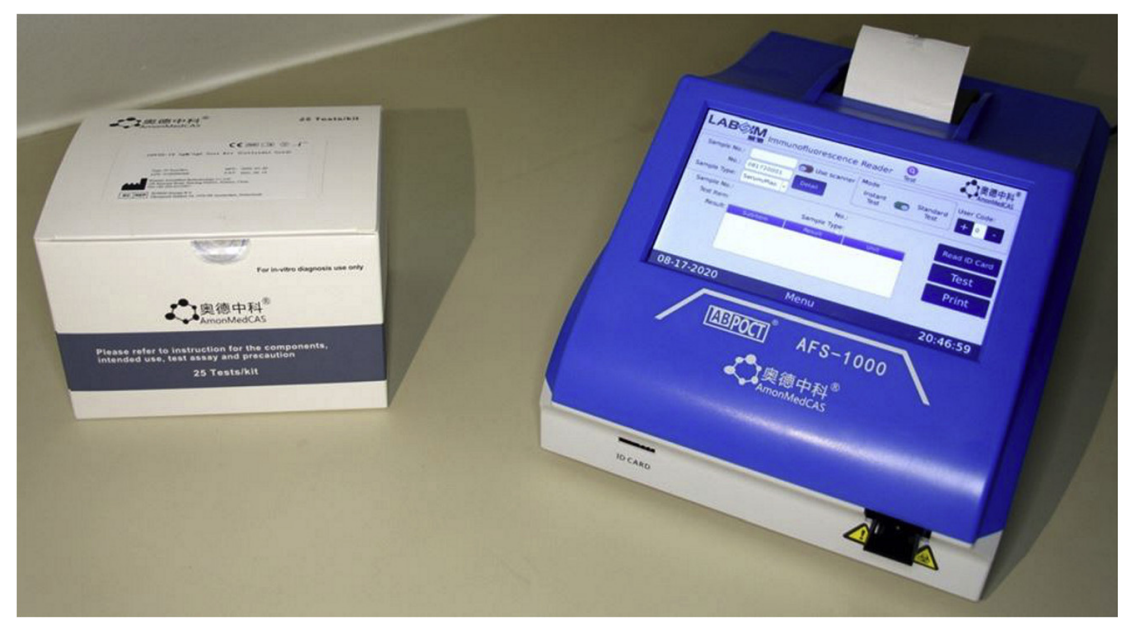

Fig. 1. The AmonMed assay test kit and the associated reader. It should be noted that the test cartridges of some batches did not fit into the reader, and therefore the evaluation had to be done with the naked eye.

acquisition for serology testing was calculated applying rank sum testing and binary logistic regression. Those calculations were performed applying the software Stata/IC 15.1 for macOS 64-bit Intel (College Station, Texas, USA).

Specificity of the serological assays was determined with the serum samples from the blood donors and the patients with EBV.

Individual missing data points were no exclusion criteria.

\section{Ethics}

Ethical clearance for this study was provided by the institutional ethics board of the University Medical Center Göttingen (Application number 21/05/20).

\section{RESULTS}

\section{Sensitivity of the serological assays as calculated with data from sample collective 1 in total and by antibody sub-class}

If a serological assay was rated positive in case of any positive signal in a COVID-19-PCR-positive patient, irrespective of the assessed antibody subclass, sensitivity of the EUROIMMUN assay was $67.4 \%$, while sensitivity of the AmonMed assay was $15.2 \%$. Assessed by antibody subclasses, EUROIMMUN IgG (immunoglobulin G) and
AmonMed IgG sensitivity were 56.5 and $0 \%$, respectively, EUROIMMUN IgA sensitivity was 54.3\%, and AmonMed IgM sensitivity was $15.2 \%$ (Table 1 ). There were no differences between results of the first and second attempt of AmonMed assay application.

Focusing on the quantitative assessment of the EUROIMMUN optical densities (OD), the mean ( \pm standard deviation (SD)) and median (interquartile range IQR) IgA ODs based on 25 positive results were $5.6( \pm 7.1)$ and $2.5(1.6,5.1)$, respectively, while for the IgGs based on 26 positive results, the values were $4.7( \pm 2.5)$ and $4.6(2.6,6.0)$, respectively.

\section{Effects of the time between positive PCR results and serum sample acquisition on the observed sensitivity}

For the 27 COVID-19-positive patients, for which the time between positive PCR result and serological testing had been recorded, the influence of time on serological test positivity was calculated using rank sum testing. As Cohen's kappa for the two attempts of AmonMed assay testing was one, meaning that their results were perfectly associated and identical, they were also considered as identical for the calculation. As shown in table two, significance of timedependence could be shown for EUROIMMUN IgG-testing, but not for any other immunoglobuline sub-class or subclass-independent overall test-positivity (Table 2).

Table 1. Sensitivity of the assessed test serological assays

\begin{tabular}{|c|c|c|c|c|c|c|c|}
\hline \multirow[b]{2}{*}{ Positive controls } & \multirow[b]{2}{*}{$n(\%)$} & \multicolumn{2}{|c|}{ EUROIMMUN assay } & \multicolumn{2}{|c|}{$\begin{array}{c}\text { AmonMed assay first } \\
\text { attempt }\end{array}$} & \multicolumn{2}{|c|}{$\begin{array}{c}\text { AmonMed assay second } \\
\text { attempt }\end{array}$} \\
\hline & & $n$ & Sensitivity $(0.95 \mathrm{CI})$ & $n$ & Sensitivity $(0.95 \mathrm{CI})$ & $n$ & Sensitivity (0.95 CI) \\
\hline Overall positives & $46(100)$ & 31 & $0.674(0.523,0.796)$ & 7 & $0.152(0.073,0.291)$ & 7 & $0.152(0.073,0.291)$ \\
\hline $\operatorname{IgA}$ & $46(100)$ & 25 & $0.543(0.396,0.684)$ & & n.a. & & n.a. \\
\hline IgG & $46(100)$ & 26 & $0.565(0.417,0.703)$ & 0 & 0 & 0 & 0 \\
\hline $\operatorname{IgM}$ & $46(100)$ & & n.a. & 7 & $0.152(0.073,0.291)$ & 7 & $0.152(0.073,0.291)$ \\
\hline
\end{tabular}

$0.95 \mathrm{CI}=95 \%$ confidence interval. $n=$ number, n.a. $=$ not applicable. 
Table 2. Rank sum testing assessment of the effects of time on serological test positivity

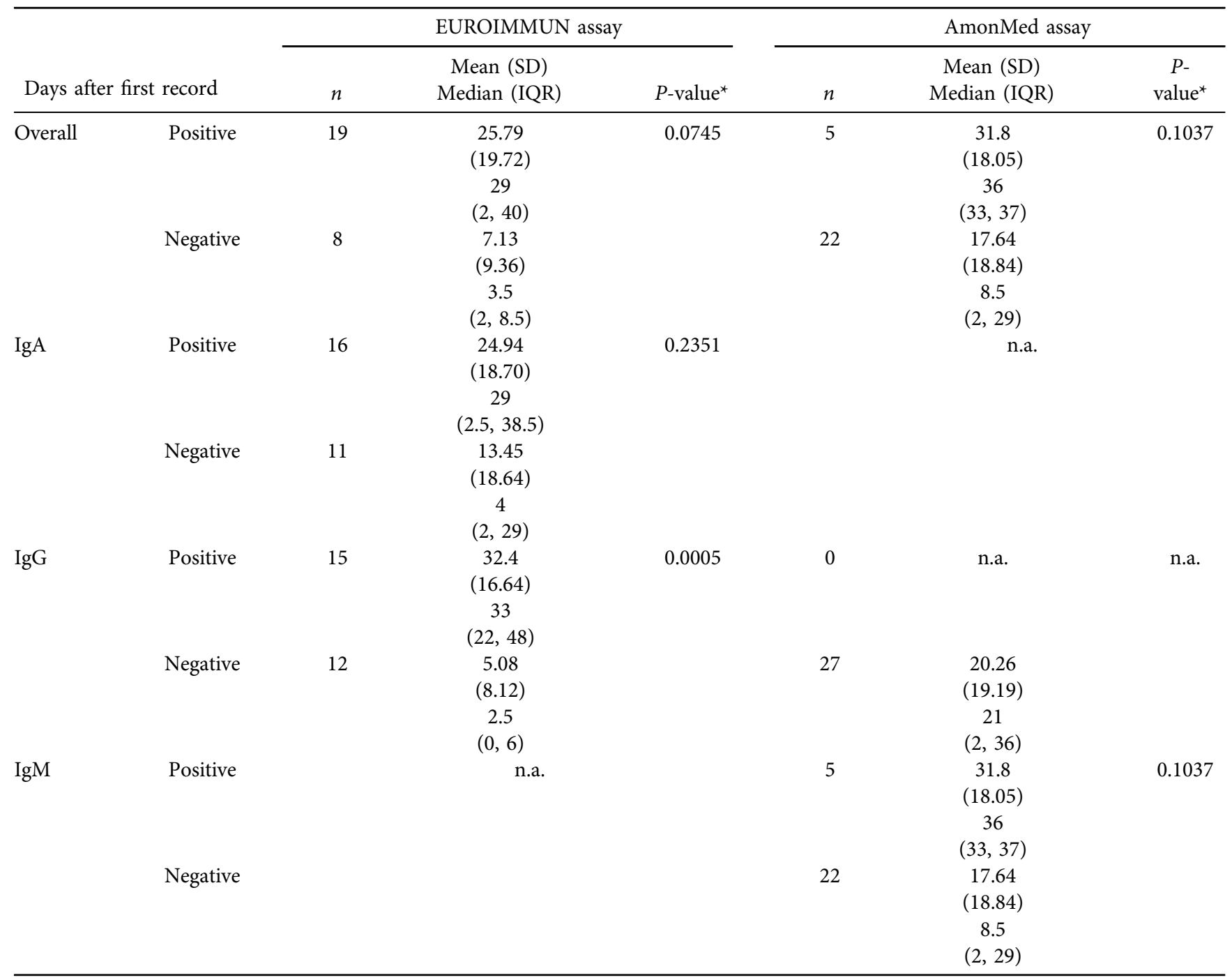

* Significance in rank sum testing.

n.a. $=$ not applicable. n.e. $=$ not estimable. $n=$ number. $\mathrm{SD}=$ standard deviation. $\mathrm{IQR}=$ interquartile range.

Similar results were achieved by binary logistic regression testing. Performing a binary logistic regression with the test results as the dependent variables and the days after a first positive PCR results as the independent variable, an increased likelihood for an overall positive test result of the Euroimmun assay is driven by EUROIMMUN IgG subclass testing (Table 3).

\section{Specificity of the serological assays as calculated with} data from the sample collectives 2 and 3 in total and by antibody sub-class

As assessed with the blood donor samples, total specificity was $97.9 \%$ for the EUROIMMUN assay and $99.0 \%$ for the AmonMed assay. Thereby, non-specificity was driven by the IgA subclass analysis of the EUROIMMUN assay with 2 false-positive results (OD values $1.1 ; 3.4$ ) and IgM subclass analysis of the AmonMed assays, while all IgG tests remained negative for both assays (Table 4).
With the sera from the $31 \mathrm{EBV}$-positive samples, similarly good specificity could be observed with only a single false positive EUROIMMUN IgA (OD value 8.0). All other test results were correctly negative, resulting in a total specificity of $96.8 \%$ for the EUROIMMUN assay and $100 \%$ for AmonMed assay (Table 5).

Table 3. Binary logistic regression assessment of the effects of time on serological test positivity

\begin{tabular}{lcccccc}
\hline \multirow{2}{*}{$\begin{array}{l}\text { Binary } \\
\text { logistic } \\
\text { regression }\end{array}$} & & \multicolumn{2}{c}{ EUROIMMUN assay } & & \multicolumn{2}{c}{ AmonMed assay } \\
\cline { 3 - 4 } \cline { 5 - 6 } & $n$ & $\begin{array}{c}\text { Coefficient } \\
(\text { SE })\end{array}$ & $\begin{array}{c}P- \\
\text { value }\end{array}$ & $\begin{array}{c}\text { Coefficient } \\
(S E)\end{array}$ & $\begin{array}{c}P \text { - } \\
\text { value }\end{array}$ \\
\hline overall & 27 & $0.074(0.036)$ & 0.038 & & 0.040 & 0.150 \\
IgA & 27 & $0.035(0.023)$ & 0.131 & & n.a. \\
IgG & 27 & $0.137(0.047)$ & 0.004 & & n.e. \\
IgM & 27 & n.a. & & 0.040 & 0.150 \\
\hline
\end{tabular}

$\mathrm{SE}=$ standard error. n.a. $=$ not applicable. n.e. $=$ not estimable. 
Table 4. Specificity of the assessed test serological assays as calculated with the blood donor sera

\begin{tabular}{|c|c|c|c|c|c|c|c|}
\hline \multirow{2}{*}{$\begin{array}{l}\text { Negative controls } \\
\text { (blood donors) }\end{array}$} & \multirow[b]{2}{*}{$N(\%)$} & \multicolumn{2}{|c|}{ EUROIMMUN assay } & \multicolumn{2}{|c|}{$\begin{array}{c}\text { AmonMed assay first } \\
\text { attempt }\end{array}$} & \multicolumn{2}{|c|}{$\begin{array}{c}\text { AmonMed assay second } \\
\text { attempt }\end{array}$} \\
\hline & & $n$ & Specificity $(0.95 \mathrm{CI})$ & $n$ & Specificity $(0.95 \mathrm{CI})$ & $n$ & Specificity $(0.95 \mathrm{CI})$ \\
\hline Overall positives & $96(100)$ & 94 & $0.979(0.919,0.995)$ & 95 & $0.990(0.928,0.999)$ & 95 & $0.990(0.928,0.999)$ \\
\hline $\operatorname{IgA}$ & $96(100)$ & 94 & $0.979(0.919,0.995)$ & & n.a. & & n.a. \\
\hline IgG & $96(100)$ & 96 & 1 & 95 & $0.990(0.928,0.999)$ & 96 & 1 \\
\hline $\operatorname{IgM}$ & $96(100)$ & & n.a. & 95 & $0.990(0.928,0.999)$ & 95 & $0.990(0.928,0.999)$ \\
\hline
\end{tabular}

$0.95 \mathrm{CI}=95 \%$ confidence interval. $n=$ number, n.a. $=$ not applicable.

Table 5. Specificity of the assessed test serological assays as calculated with the blood donor sera

\begin{tabular}{|c|c|c|c|c|c|c|c|}
\hline \multirow{2}{*}{$\begin{array}{l}\text { Negative controls } \\
\text { (EBV) }\end{array}$} & \multirow[b]{2}{*}{$N(\%)$} & \multicolumn{2}{|c|}{ EUROIMMUN assay } & \multicolumn{2}{|c|}{$\begin{array}{c}\text { AmonMed assay first } \\
\text { attempt }\end{array}$} & \multicolumn{2}{|c|}{$\begin{array}{c}\text { AmonMed assay second } \\
\text { attempt }\end{array}$} \\
\hline & & $n$ & Specificity $(0.95 \mathrm{CI})$ & $n$ & Specificity $(0.95 \mathrm{CI})$ & $n$ & Specificity $(0.95 \mathrm{CI})$ \\
\hline Overall positives & $31(100)$ & 30 & $0.968(0.790,0.996)$ & 31 & 1 & 31 & 1 \\
\hline $\operatorname{IgA}$ & $31(100)$ & 30 & $0.968(0.790,0.996)$ & \multicolumn{2}{|r|}{ n.a. } & \multicolumn{2}{|r|}{ n.a. } \\
\hline IgG & $31(100)$ & 31 & 1 & 31 & 1 & 31 & 1 \\
\hline $\operatorname{IgM}$ & $31(100)$ & & n.a. & 31 & 1 & 31 & 1 \\
\hline
\end{tabular}

$0.95 \mathrm{CI}=95 \%$ confidence interval. $n=$ number, n.a. $=$ not applicable.

\section{DISCUSSION}

The study was performed in order to assess the performance characteristics of the serological RDT COVID-19 IgM/IgG test kit (Colloidal gold/AmonMed assay) for the surveillance of recent SARS-CoV-2 infections compared with a standard benchtop approach by EUROIMMUN. In a group of 46 COVID-19-PCR positive patients, however, sensitivity of the AmonMed assay was as poor as $15.2 \%$ and only IgM-driven, in spite of time periods up to 60 days between positive PCRtesting and serum sample acquisition, with a median of three weeks. Due to a complete lack of positive IgG results in AmonMed testing, Cohen's kappa [54] for a comparison of the AmonMed assay with the EUROIMMUN assay could not be calculated. No time dependency of positive results in AmonMed assay testing could be shown, which was only detectable for EUROIMMUN IgG. The previously described EUROIMMUN IgA-specificity problems could be confirmed by this study as well [42-53]. The AmonMed assay's specificity, however, was excellent as assessed both with blood donor sera and sera taken from EBV patients.

Regarding the practical diagnostic application of the AmonMed assay, the following aspects should be considered. In case of high pandemic activity, the challenge is the rapid identification of subpopulations, within which at least one individual has been infected with COVID-19. In particular, rapid diagnoses are desired in order not to unnecessarily restrict the freedom of the examined individuals on the one hand and on the other hand to protect the society against the risk of infection. Indeed, the POCT tests examined are particularly suitable for this, because they have a very high specificity, which is the basic requirement for screening tests in order to serve the goal as outlined above, i.e. the protection of both the individual and the society. At the same time, a low sensitivity can be accepted as long as the test results are considered only to refer to the examined population as a whole, while the individual's diagnosis is set applying a sufficiently sensitive test. Sensitivity on population level, which is the probability of detecting at least one infected individual within the tested population, is defined by the algorithms of multiple-testing and thus much higher than sensitivity for an individual sample [5]. The same applies to specificity on population level, which is the probability of not detecting a single positive result in the tested population, if there is no infected individual there. Considering this, the assessed POCT tests are therefore very suitable for rapid decision making on whether or not there have been infected individuals in a population of interest. However, the test is unsuitable for individual diagnoses. The resulting decision algorithm could be: A population can be considered as infected, if at least one POCT test is positive. In contrast, a population can be considered as free of infections beyond the diagnostic window period if all tests are negative. For the latter issue, the observed perfect specificity is crucial.

The study has a number of limitations. First of all, patients infected with SARS-CoV-2 were identified by PCRbased tests, which may also produce false positive results. However, the possibility of a false positive result was minimized by sequential confirmation of the results with a second PCR-based test. A total of three different targets were detected in the virus genome. Secondly, the EUROIMMUN assay, which was used for comparison purposes, cannot be considered as a gold standard, as its sensitivity and specificity are different from $100 \%$ themselves [31, 32, 42-53]. Thirdly, the EBV-positive samples, which were included in the specificity assessment, were collected during the time period when the COVID-19 pandemic had already reached Germany. Considering the very low COVID-19 prevalence 
of less than $1 \%$ in Germany when the study was conducted, as well as the very low number of assessed EBV-positive patients, co-infection with SARS-CoV-2 among the EBV-patients is virtually excluded. This is also the case for the single individual with a positive IgA in the EUROIMMUN assay. Finally, ethical clearance did not allow any assessment and presentation of patient data, which necessarily resulted in disagreement with the STARD reporting standard for test comparisons [55] and made comparisons with patient characteristics, which has recently been shown to be promising [40], impossible.

In spite of those limitations, the assessment confirmed considerable sensitivity weakness of the assessed RDT in spite of good specificity.

\section{CONCLUSIONS}

Due to low sensitivity, the assessed RDT AmonMed assay cannot be recommended for diagnostic or surveillance purposes. If such applications are, however, nevertheless considered, the observed very good specificity at least suggests reliability of positive results in an epidemic setting with acceptable pre-test probability, while negative results should always be confirmed by another assay.

Funding sources: The APC was funded by the Open Access Support Program of the Deutsche Forschungsgemeinschaft and the publication fund of the Georg-August-Universität Göttingen.

Authors' contribution: Conceptualization, A.E.Z.; methodology, A.E.Z.; software, A.E.Z.; validation, A.E.Z.; formal analysis, A.H.; investigation, A.D., A.H., J.S., A.E.Z.; resources, A.H., S.B., U.G., A.E.Z.; data curation, A.E.Z.; writing-original draft preparation, A.D., H.F., A.E.Z.; writing-review and editing, A.D., J.S., H.F., A.E.Z.; visualization, A.H., A.E.Z.; supervision, A.E.Z.; project administration, U.G., S.B., A.E.Z.; funding acquisition, A.E.Z. All authors have read and agreed to the published version of the manuscript.

Conflict of interest: The authors declare no conflict of interest. The funders had no role in the design of the study; in the collection, analyses, or interpretation of data; in the writing of the manuscript, or in the decision to publish the results.

\section{ACKNOWLEDGMENTS}

Patient data collection was supported by the study nurse Irina Pavlova, Interdisciplinary Emergency Department, University Medical Center Göttingen.

\section{SUPPLEMENTARY MATERIAL}

Supplementary data to this article can be found online at https://doi.org/10.1556/1886.2020.00029.

\section{REFERENCES}

1. Zhou P, Yang XL, Wang XG, Hu B, Zhang L, Zhang W, et al. A pneumonia outbreak associated with a new coronavirus of probable bat origin. Nature 2020;579:270-3.

2. Hahn A, Hinz R, Meyer T, Loderstädt U, Herchenröder O, Meyer $\mathrm{CG}$, et al. HIV prevention strategies and risk of infection: A modelbased analysis. Epidemiol Infect 2018;146:1015-25.

3. Hahn A, Hinz R, Meyer T, Loderstädt U, Herchenröder O, Meyer $\mathrm{CG}$, et al. Diagnostics as prevention - A rapid testing-based strategy of sex workers against sexual HIV exposure. Eur J Microbiol Immunol (Bp) 2018;8:47-52.

4. Frickmann H. Diversification of the prevention of sexually transmitted infections. Future Microbiol 2019;14:1465-8.

5. Hahn A, Schwarz NG, Meyer T, Frickmann H. PCR-based rapid diagnostic tests as a strategy for preventing infections with sexually transmitted diseases-a "diagnostics-as-prevention" modelling approach. Lett Appl Microbiol 2018;67:420-4.

6. Hahn A, Kröger C, Meyer CG, Loderstädt U, Meyer T, Frickmann $\mathrm{H}$, et al. Comparison of self-reported sexual activity among heterosexuals with sexual spread of poorly transmittable agents: A minimalistic approach to estimating sexual activity based on HIV incidence. Int J Environ Res Public Health 2020;17:5504.

7. Corman VM, Landt O, Kaiser M, Molenkamp R, Meijer A, Chu DK, et al. Detection of 2019 novel coronavirus (2019-nCoV) by real-time RT-PCR. Euro Surveill 2020;25:2000045.

8. Moran A, Beavis KG, Matushek SM, Ciaglia C, Francois N, Tesic V, et al. Detection of SARS-CoV-2 by use of the Cepheid Xpert Xpress SARS-CoV-2 and Roche cobas SARS-CoV-2 assays. J Clin Microbiol 2020;58:e00772-20.

9. Broder K, Babiker A, Myers C, White T, Jones H, Cardella J, et al. Test agreement between Roche Cobas 6800 and Cepheid GeneXpert Xpress SARS-CoV-2 assays at high cycle threshold ranges. J Clin Microbiol 2020;58:e01187-20.

10. Loeffelholz MJ, Alland D, Butler-Wu SM, Pandey U, Perno CF, Nava A, et al. Multicenter evaluation of the cepheid Xpert Xpress SARS-CoV-2 test. J Clin Microbiol 2020;58:e00926-20.

11. Wolters F, van de Bovenkamp J, van den Bosch B, van den Brink S, Broeders $\mathrm{M}$, Chung $\mathrm{NH}$, et al. Multi-center evaluation of cepheid xpert $^{(B)}$ xpress SARS-CoV-2 point-of-care test during the SARSCoV-2 pandemic. J Clin Virol 2020;128:104426.

12. Lowe CF, Matic N, Ritchie G, Lawson T, Stefanovic A, Champagne $\mathrm{S}$, et al. Detection of low levels of SARS-CoV-2 RNA from nasopharyngeal swabs using three commercial molecular assays. J Clin Virol 2020;128:104387.

13. Smithgall MC, Scherberkova I, Whittier S, Green DA. Comparison of Cepheid Xpert Xpress and Abbott ID now to roche cobas for the rapid detection of SARS-CoV-2. J Clin Virol 2020;128:104428.

14. Tanida K, Koste L, Koenig C, Wenzel W, Fritsch A, Frickmann H. Evaluation of the automated cartridge-based ARIES SARS-CoV-2 Assay (RUO) against automated Cepheid Xpert Xpress SARS-CoV2 PCR as gold standard. Eur J Microbiol Immunol (Bp) 2020; [Epub ahead of print]. https://doi.org/10.1556/1886.2020.00017.

15. Harrington A, Cox B, Snowdon J, Bakst J, Ley E, Grajales P, et al. Comparison of Abbott ID Now and Abbott m2000 Methods for the detection of SARS-CoV-2 from nasopharyngeal and nasal swabs from symptomatic patients. J Clin Microbiol 2020;58:e00798-20. 
16. Rhoads DD, Cherian SS, Roman K, Stempak LM, Schmotzer CL, Sadri N. Comparison of Abbott ID now, DiaSorin Simplexa, and CDC FDA emergency use authorization methods for the detection of SARS-CoV-2 from Nasopharyngeal and Nasal Swabs from Individuals diagnosed with COVID-19. J Clin Microbiol 2020;58: e00760-20.

17. Zhen W, Smith E, Manji R, Schron D, Berry GJ. Clinical evaluation of three sample-to-answer platforms for detection of SARS-CoV-2. J Clin Microbiol 2020;58:e00783-20.

18. Basu A, Zinger T, Inglima K, Woo KM, Atie O, Yurasits L, et al. Performance of Abbott ID Now COVID-19 rapid nucleic acid amplification test using nasopharyngeal swabs transported in viral transport media and dry nasal swabs in a New York City academic institution. J Clin Microbiol 2020;58:e01136-20.

19. Santiago I. Trends and innovations in biosensors for COVID-19 mass testing. Chembiochem 2020; [Epub ahead of print]. https:// doi.org/10.1002/cbic.202000250.

20. Park A, Iwasaki A. Type I and Type III interferons - Induction, signaling, evasion, and application to combat COVID-19. Cell Host Microbe 2020;27:870-8.

21. Wang Q, Du Q, Guo B, Mu D, Lu X, Ma Q, et al. A method to prevent SARS-CoV-2 IgM false positives in gold immunochromatography and enzyme-linked immunosorbent assays. J Clin Microbiol 2020;58:e00375-20.

22. Zhang ZL, Hou YL, Li DT, Li FZ. Diagnostic efficacy of anti-SARSCoV-2 IgG/IgM test for COVID-19: A meta-analysis. J Med Virol 2020; [Epub ahead of print]. https://doi.org/10.1002/jmv.26211.

23. Shen B, Zheng Y, Zhang X, Zhang W, Wang D, Jin J, et al. Clinical evaluation of a rapid colloidal gold immunochromatography assay for SARS-Cov-2 IgM/IgG. Am J Transl Res 2020;12:1348-54.

24. Choe JY, Kim JW, Kwon HH, Hong HL, Jung CY, Jeon CH, et al. Diagnostic performance of immunochromatography assay for rapid detection of IgM and IgG in coronavirus disease 2019. J Med Virol 2020; [Epub ahead of print]. https://doi.org/10.1002/jmv.26060.

25. Laureano AFS, Riboldi M. The different tests for the diagnosis of COVID-19 - A review in Brazil so far. JBRA Assist Reprod 2020;24: 340-6.

26. Li H, Liu Z, He Y, Qi Y, Chen J, Ma Y, et al. A new and rapid approach for detecting COVID-19 based on S1 protein fragments. Clin Transl Med 2020;10:e90. https://doi.org/10.1002/ctm2.90.

27. Huang C, Wen T, Shi FJ, Zeng XY, Jiao YJ. Rapid detection of IgM antibodies against the SARS-CoV-2 virus via colloidal gold nanoparticle-based lateral-flow assay. ACS Omega 2020;5:12550-6.

28. Xue X, Zhu C, Huang S, Pan L, Xu J, Li W. Effect of heat inactivation of blood samples on the efficacy of three detection methods of SARS-CoV-2 antibodies. Nan Fang Yi Ke Da Xue Xue Bao 2020; 40:316-20.

29. Kaneko S, Nukui Y, Arashiro T, Aiso Y, Sugii M, Hadano Y, et al. Clinical validation of an immunochromatographic SARS-Cov-2 IgM/IgG antibody assay with Japanese cohort. J Med Virol 2020; [Epub ahead of print]. https://doi.org/10.1002/jmv.26363.

30. Bernasconi L, Oberle M, Gisler V, Ottiger C, Fankhauser H, Schuetz $\mathrm{P}$, et al. Diagnostic performance of a SARS-CoV-2 IgG/IgM lateral flow immunochromatography assay in symptomatic patients presenting to the emergency department. Clin Chem Lab Med 2020; [Epub ahead of print]. https://doi.org/10.1515/cclm-2020-0635.

31. Andrey DO, Cohen P, Meyer B, Torriani G, Yerly S, Mazza L, et al. Diagnostic accuracy of Augurix COVID-19 IgG serology rapid test.
Eur J Clin Invest 2020; [Epub ahead of print]. https://doi.org/10. 1111/eci.13357.

32. Andrey DO, Cohen P, Meyer B, Torriani G, Yerly S, Mazza L, et al. Head-to-head accuracy comparison of three commercial COVID19 IgM/IgG serology rapid tests. J Clin Med 2020;9:E2369.

33. de la Iglesia J, Fernández-Villa T, Fegeneda-Grandes JM, GómezGarcía M, Majo García R, López Sanz S, et al. Concordance between two rapid diagnostic tests for the detection of antibodies against SARS-CoV-2. Semergen 2020;1:21-5. https://doi.org/10. 1016/j.semerg.2020.06.009.

34. Zainol Rashid Z, Othman SN, Abdul Samat MN, Ali UK, Wong KK. Diagnostic performance of COVID-19 serology assays. Malays J Pathol 2020;42:13-21.

35. Lai CC, Wang CY, Ko WC, Hsueh PR. In vitro diagnostics of coronavirus disease 2019: Technologies and application. J Microbiol Immunol Infect 2020; [Epub ahead of print]. https://doi.org/10. 1016/j.jmii.2020.05.016.

36. Ravi N, Cortade DL, Ng E, Wang SX. Diagnostics for SARS-CoV-2 detection: A comprehensive review of the FDA-EUA COVID-19 testing landscape. Biosens Bioelectron 2020;165:112454.

37. Nelson PP, Rath BA, Fragkou PC, Antalis E, Tsiodras S, Skevaki C. Current and future point-of-care tests for emerging and new respiratory viruses and future perspectives. Front Cell Infect Microbiol 2020;10:181.

38. Gaddi AV, Capello F, Aluigi L, Antignani PL, Callegaro A, Casu G, et al. The strategic alliance between clinical and molecular science in the war against SARS-CoV-2, with the rapid-diagnostics test as an indispensable weapon for front line doctors. Int J Mol Sci 2020; 21:4446.

39. Ghaffari A, Meurant R, Ardakani A. COVID-19 serological tests: how well do they actually perform? Diagnostics (Basel) 2020;10: E453.

40. Gorse GJ, Donovan MM, Patel GB. Antibodies to coronaviruses are higher in older compared with younger adults and binding antibodies are more sensitive than neutralizing antibodies in identifying coronavirus-associated illnesses. J Med Virol 2020;92: 512-17.

41. Che XY, Qiu LW, Liao ZY, Wang YD, Wen K, Pan YX, et al. Antigenic cross-reactivity between severe acute respiratory syndrome-associated coronavirus and human coronaviruses 229E and OC43. J Infect Dis 2005;191:2033-7.

42. Jääskeläinen $A J$, Kuivanen $S$, Kekäläinen $E$, Ahava $M J$, Loginov R, Kallio-Kokko H, et al. Performance of six SARS-CoV-2 immunoassays in comparison with microneutralisation. J Clin Virol 2020; 129:104512.

43. Tang MS, Hock KG, Logsdon NM, Hayes JE, Gronowski AM, Anderson NW, et al. Clinical performance of two SARS-CoV-2 serologic assays. Clin Chem 2020;66:1055-62.

44. Beavis KG, Matushek SM, Abeleda APF, Bethel C, Hunt C, Gillen S, et al. Evaluation of the EUROIMMUN Anti-SARS-CoV-2 ELISA Assay for detection of IgA and IgG antibodies. J Clin Virol 2020; 129:104468.

45. Meyer B, Torriani G, Yerly S, Mazza L, Calame A, Arm-Vernez I, et al. Validation of a commercially available SARS-CoV-2 serological immunoassay. Clin Microbiol Infect 2020;26:1386-94. https://doi.org/10.1016/j.cmi.2020.06.024.

46. Jääskeläinen AJ, Kekäläinen E, Kallio-Kokko H, Mannonen L, Kortela E, Vapalahti O, et al. Evaluation of commercial and 
automated SARS-CoV-2 IgG and IgA ELISAs using coronavirus disease (COVID-19) patient samples. Euro Surveill 2020;25: 2000603.

47. Theel ES, Harring J, Hilgart H, Granger D. Performance characteristics of four high-throughput immunoassays for detection of IgG antibodies against SARS-CoV-2. J Clin Microbiol 2020;58: e01243-20.

48. Weidner L, Gänsdorfer S, Unterweger S, Weseslindtner L, Drexler C, Farcet M, et al. Quantification of SARS-CoV-2 antibodies with eight commercially available immunoassays. J Clin Virol 2020;129: 104540.

49. Haselmann V, Kittel M, Gerhards C, Thiaucourt M, Eichner R, Costina V, et al. Comparison of test performance of commercial anti-SARS-CoV-2 immunoassays in serum and plasma samples. Clin Chim Acta 2020;510:73-8.

50. Plebani M, Padoan A, Negrini, D, Carpinteri B, Sciacovelli L. Diagnostic performances and thresholds: The key to harmonization in serological SARS-CoV-2 assays? Clin Chim Acta 2020; 509:1-7.
51. Hörber S, Soldo J, Relker L, Jürgens S, Guther J, Peter S, et al. Evaluation of three fully-automated SARS-CoV-2 antibody assays. Clin Chem Lab Med 2020; [Epub ahead of print]. https://doi.org/ 10.1515/cclm-2020-0975.

52. Charlton CL, Kanji JN, Johal K, Bailey A, Plitt SS, MacDonald C, et al. Evaluation of six commercial mid to high volume antibody and six point of care lateral flow assays for detection of SARS-CoV2 antibodies. J Clin Microbiol 2020; [Epub ahead of print]. https:// doi.org/10.1128/JCM.01361-20.

53. Schnurra C, Reiners N, Biemann R, Kaiser T, Trawinski H, Jassoy C. Comparison of the diagnostic sensitivity of SARS-CoV-2 nucleoprotein and glycoprotein-based antibody tests. J Clin Virol 2020;129:104544.

54. Landis JR, Koch GG. The measurement of observer agreement for categorical data. Biometrics. 1977;33:159-74.

55. Cohen JF, Korevaar DA, Altman DG, Bruns DE, Gatsonis CA, Hooft L, et al. STARD 2015 guidelines for reporting diagnostic accuracy studies: Explanation and elaboration. BMJ Open 2016;6: e012799. 